\title{
the Analysis, Discussion and Suggestions for the Mesh Reinforcement Technique of Polymer Mortar Wire Rope
}

\author{
Shuren Zhang ${ }^{1,2, a}$, Zhonglong $\mathrm{Li}^{1,2, b}$ \\ ( ${ }^{1}$ School of Transportation Science and Engineering, Harbin Institute of Technology, Key \\ Laboratory of traffic safety, specialty materials and intelligent control technology transportation \\ industry Harbin 150090, China; \\ 2.Postdoctoral Station of Mechanics, Harbin Institute of Technology, Harbin 150090, China) \\ a18745059800@126.com, blizhonglong2004@126.com
}

\section{Keyword: Piece of steel wire rope course, Polymer mortar, Bonded prestress, Reinforcement}

\begin{abstract}
The mesh reinforcement technique of polymer mortar wire rope is a new reinforcement technique used more in the domestic fittest reinforcement project recent years. Recently, there are no unified technical standards, the detailed practice is not same in practical work. There are big differences among the reinforcement effects. The key issue is whether or not to impose the prestressed steel wire rope and the prestressed size. The difference of the actual practice and reinforcement effect reflects the understanding gap polymer mortar wire rope of mesh reinforcement technique action principle of the designer. A correct understanding of polymer mortar wire rope of mesh reinforcement technique the mechanism and the objective analysis strengthening effect and actively explore research in engineering application problems have a practical significance to promote the healthy development of the structure strengthening technology.
\end{abstract}

\section{Analysis of the polymer mortar reinforcement mechanism of wire rope nets}

There are a lot of methods to reinforce the weak component in practical engineering, According to the mechanism, they can be reinforced two big kinds of passive reinforcement and active reinforcement [1] .

Passive reinforcement for the kind of direct reinforcement. Direct reinforcement reinforcement refers to adding tensile (or shear) reinforcing materials in the weak area of the tension in the component (or shear).Adding more strong material after the reinforcement method assume only live load and add after the internal cause constant load. Compared with the original beams reinforced, the following reinforcing materials should be strain lag. In Common Circumstances in the limit state, It should be less than the eed tensile strength limitation .The high tensile properties of the wire rope is unable to give full play to the role. It is a kind of great waste.

Prestressed reinforcement initiatively. Prestressed reinforcement initiatively refers to a prestressed concrete reinforcing system which adding reinforcing materials prestress in the tension zone (or shear weak area) where reinforced. Then spray note high-powered composite mortar, combine the reinforced beam body with the integration unbonded. When we reinforce the steel wire mesh in polymer mortar, if prestressed concrete to the wire rope, it also called polymer mortar prestressed reinforcement of mesh wire rope, This reinforcement method belongs to the active principle from strengthening category. The main purpose to add more material prestress is to solve reinforcing materials "strain lag" from the fundamental, improve the efficiency in the use of materials, after that, the original beams of the stress state is improved, the original beams of the bearing capacity and crack resistance is enhanced.

The application of the high-powered composite reinforcement fabric mortar (HPF) strengthening technology.

Liangtao $\mathrm{Bu}$ come up with the high-powered composite mortar proposed reinforcement fabric (HPF) strengthening technology in the book the new technology of the high-powered composite mortar steel reinforced concrete structure $(H P F)$, using the ordinary hot rolling steel instead of the 
high strength steel wire nets, The reinforcement effect is equal with no adding prestressed polymer mortar wire rope nets piece of reinforcement. But the structure is more simple, construction is more convenient, and the reinforcement cost also reduced [2].

Even though high-powered composite mortar (polymer mortar) steel reinforcement technique belongs to passive reinforcement category, it's plastic performance is good because the ordinary tensile strength the hot rolling steel used is relatively low. for strengthening the medium and small span of the reinforced concrete beam board which is little influenced by "add after reinforcing materials strain lag", The ultimate state reinforcing steel bar add after the stress basically can achieve (or close to) the tensile strength limit it still can improve the bearing capacity and structure and rich the purpose of durability. High-powered composite mortar (polymer mortar) steel reinforcement technique especially suitable for the reinforcement of the reinforced concrete column. Axial force after strengthened beam of longitudinal reinforcement in the ultimate state of stress, can achieve the compressive strength of the design value. Furthermore, the reinforcement method has the characteristics of constraint reinforcement, it can limit the lateral deformation of the core concrete, then make concrete in a three stressed statement. Indirectly improved the structure of the concrete compressive strengthen, that can get the purpose of improving the structure of bearing capacity and durability double strengthening.

\section{Rationality analysis for adopting the wire rope nets of prestressed reinforcement.}

Theory of research and engineering practice shows that the prestressed reinforced used by prestressed concrete must use high strength reinforced whose stress relaxation smaller. General use of the high strength steel wire, steel strand and fine rolling steel rebar. Wire rope is a kind of high strength tensile materials with flexibility, it is mainly used for the engineering of lifting and raction. In recent years, it is a new attempt of the polymer mortar prestressed reinforcement technique of wire rope nets to wire rope for prestressed reinforcing the fittest reinforcement project. Its main advantage is: The anchor wire rope connection anchor structure is simple, (Put the wire rope end through a bolt of the ring at the end of the hole, fixed with the card after the enfoldment.) Wire rope has certain the flexibility so that it can adapt to the needs of different shape structure reinforcement. The main problem using the prestressed steel wire rope is still lack of necessary understanding to the wire rope stress relaxation performance. According to some manufacturers, the wire rope stress relaxation rate at $10 \%$, the recent test results by Harbin Institute of Technology is similar to the numerical.

The test measuring the strain with the frequency method, the initial tension strain of wire rope 1 turns to $6458 \mu \varepsilon$, The corresponding tension control stress for $936.4 \mathrm{MPa}$. It equals 0.6 times the tensile strength standard values. the initial tension strain of wire rope 2 turns to $6458 \mu \varepsilon$, The corresponding tension control stress for 1073.0MPa. It equals 0.7 times the tensile strength standard values. 77 days after the measurement of 1 , the stress of wire rope loss rate is about $19.24 \%$, the stress of wire rope 2 loss rate is about $20.62 \%$.

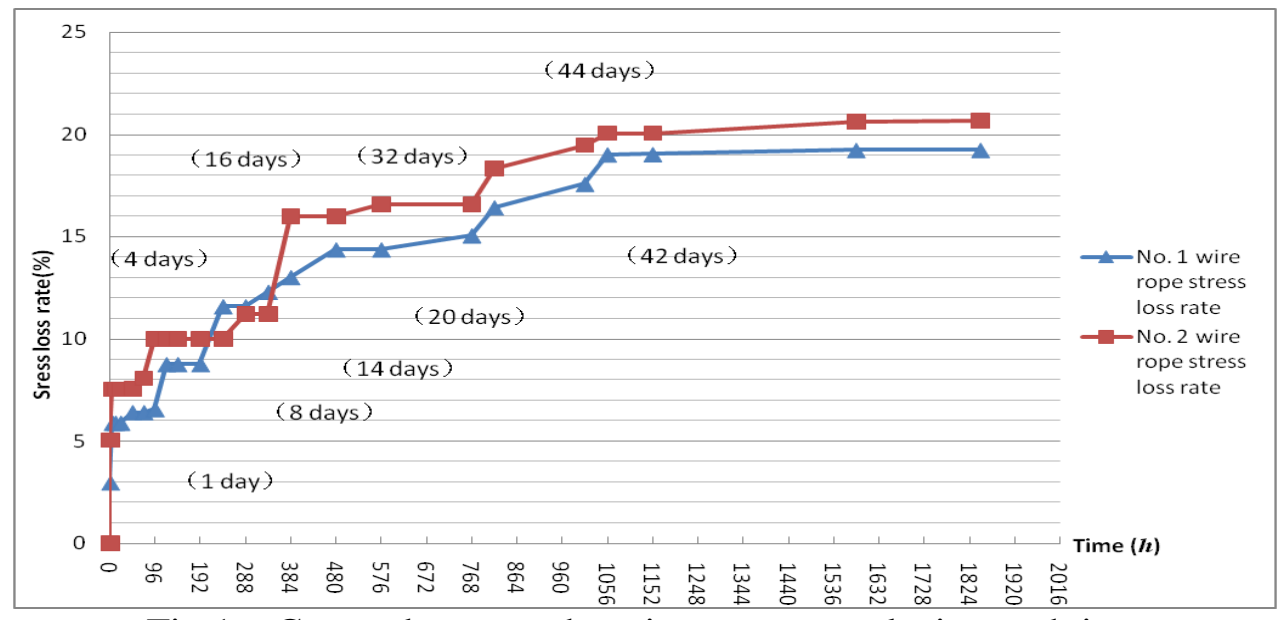

Fig.1 Curves between the wire rope stress losing and time 
Fig. 1 shows for the wire rope stress and the relationship between the time loss rate curve, wire rope 2 shows $4 \sim 14$ days of stress stable loss at around 10\%. 14 days later the loss rate increase, 44 days later it basically stable, wire rope 1 shows $4 \sim 14$ days of stress stable loss at around $8 \%, 8$ days later the loss rate will suddenly increase, 42 days later it basically stable.

There is something should be point out, The trial of measured stress losses including: The wire rope stress relaxation loss and card fixture sliding deformation loss in two parts, Among them what proportion of their respective is difficult to accurately dividing, it analyzed that 4 14days(or $5 \sim 8$ days) trend to the stable $10 \%$, which is basically belongs to the stress relaxation loss, then rapid development of late stress losses reflect the characteristics of deformation sliding loss. The trial results are not accurate though stress relaxation of the loss of the value, But the conclusion through stress wire rope given by the test loss rate as high as $20 \%$ better reflect engineering used in the actual stress of wire rope net loss of the overall situation, The author thinks that the loss rate of stress as much as $20 \%$ of the prestressed steel wire rope for not be appropriate.

In addition, turn the wire rope into nets how exactly to carry on prestressed drawing work is also worth to discuss. Due to the limit by the construction equipment construction is only single (or a few root) partial tension, when push and pull in mesh nodes place it will produce friction which may cause the distortion of the node deformation or destroyed, These will affect the work of the structure performance after the effective and strengthening the tension of wire rope prestress value, The author thinks that we should put the view on the prestressed tendon layout and simplify construction. It is not necessary to take wire rope into nets in advance. the reinforcement of One way to force on both sides of the plate for normal section flexural strength just need in the longitudinal decorate wire rope, it according to decorate distribution reinforced In a horizontal structure requirement, when we make normal section flexural reinforcing to the stress of two-way four supporting board of the bearing capacity, should decorate wire rope in two directions, after wire rope tension, will the longitudinal and lateral wire rope nodes and locally, Wire rope tension after the first binding into nets can avoid node of the distortion of the influence of tension.

\section{The key technology with the unbonded prestressed concrete reinforcement.}

The system which the anchor in reinforced beam body on small diameter steel strand or ordinary hot rolling steel, beam on the strength of the body, then spray note high-performance tensile composite mortar is the author's new idea reinforcement design which summarized in 2004 in South Korea SRAP technology. The key techniques are tendons tension and anchoring and high strength compound the reasonable selection of mortar and injection.

The choice, tension and anchoring of prestressed reinforcing steel. There are many kinds of restressed reinforcing steelused for bonded prestressing tendons, In practical projects it should be based on strengthening the nature and structure of the force requirements, comprehensive considerate the environment of the structural use, conditions of the reinforcing construction, tension and anchored structure reinforcement cost, and other factors to choose the type of prestressed reinforcement.

Prestressed reinforcing steel used for bonded prestressing tendons can use small diameter and low relaxationsteel strand, fine rolling rebar and other domestic steel. Because of the old bridge reinforcement for prestressed tendon stress less loss of domestic steel, tension control stress is low, In some cases even can use small diameter of ordinary hot rolling steel (HRB400 or HRB335) and epoxy coating ordinary hot rolling steel (HRB400 or HRB335). The biggest advantage using common hot-rolled steel is can use welding anchor. Using the epoxy coatings hot-rolled steel with a certain ability of anticorrosive can reduce tensile strength requirement of the gush note composite mortar. The fixation of small diameter steel strand and fine rolling rebar prestressed anchor the load on the body of supporting angle steel, construction is simple, and the project cost is low.

Small diameter steel strand of the clip anchorage anchor to lower the project cost, using small jack to tension, Tension control stress could take $f_{p k}$ from $\sigma_{c o n}=0.5 \sim 0.6 f_{p k}$ as the prestressed tensile strength standard values. Small diameter fine rolling rebar adopt nuts anchor which from the 
manufacturer. Using small hydraulic force measurement wrench to tension, Tension control stress can take $\sigma_{c o n}=(0.7 \sim 0.8) f_{p k}$, small diameter hot rolling steel (HRB400 or HRB335) welding connection anchor. Welding both ends of the steel to steel bar which is fixed in reinforced beam on the body. By adopting transverse taut deformation of tension, Tension control stress desirable and a period load the original beams reinforced stress to roughly the same level. Generally take $\sigma_{c o n}=(0.4 \sim 0.6) f_{p k}$.

The choice and injection of the high performance tensile composite mortar. The high performance tensile composite mortar injected with the depending on the unbonded prestressed concrete reinforcing system, prestressed reinforced beam body with a binding, it is the foundation to ensure they two work together that composite cement mortar high adhesive strength. The high tensile properties of composite cement mortar is the premise which can control structure anticrack , protect prestressed reinforced from corrosion.

Currently there is a lot of high performance domestic production composite mortar, There is still no uniform production standards. the performance indexes given by manufacturersare also different. The author suggested that the high performance concrete used for the inforcement composite mortar should meet the provisions of performance requirements in the table 1[3-4].

Table 1 The main performance requirements CMMR used for structure reinforcement

\begin{tabular}{|l|c|c|c|c|c|}
\hline $\begin{array}{c}\text { Mortar } \\
\text { performance } \\
\text { Points level }\end{array}$ & $\begin{array}{c}\text { The standard } \\
\text { values of the } \\
\text { compressive } \\
\text { strength } \\
{[\mathrm{MPa}]}\end{array}$ & $\begin{array}{c}\text { Tensile strength } \\
\text { standard values } \\
\text { [MPa] }\end{array}$ & $\begin{array}{c}\text { Surface bonding } \\
\text { shear strength } \\
\text { standard values } \\
{[\mathrm{MPa}]}\end{array}$ & $\begin{array}{c}\text { Standard } \\
\text { carbonation } \\
\text { depth } \\
{[\mathrm{mm}]}\end{array}$ & $\begin{array}{c}\text { Chloride permeability } \\
\text { [the coulomb's] }\end{array}$ \\
\hline Level 1 & $\nless 35$ & $\nless 8$ & $\nless 3$ & $\ngtr 5$ & Very low(100-1000) \\
\hline Level 2 & $\nless 30$ & $\nless 6$ & $\nless 2.5$ & $\ngtr 8$ & Very low $(100-1000)$ \\
\hline Level 3 & $\nless 30$ & $\nless 4$ & $\nless 2$ & $\ngtr 10$ & low $(1000-2000)$ \\
\hline Level 4 & $\nless 30$ & $\nless 3$ & $\nless 1.5$ & $\ngtr 15$ & low $(1000-2000)$ \\
\hline
\end{tabular}

The choice of composite mortar shall be comprehensive consideration of the structure of the use of the environment, the reinforcement design resistance requirements and strengthening the effects of the construction, the proposal to the following opinions treatment:

(1)Reinforced for cross-section bending in the bottom of the load in the tension zone.

(1) strengthen with the bonded prestressing of the small diameter steel strand, high strength steel wire and fine rolling steel rebar. In one, two kind of environment of the structure, can use level 2 compound mortar. In three, four categories of the environment of the structure appropriate USES level 1 composite mortar.

(2) Strengthen with the bonded prestressing in using common hot-rolled steel(HRB335,HRB400):

In one, two kind of environment of the structure, can use level 3compound mortar. In three, four categories of the environment of the structure appropriate USES level 2 composite mortar.

(2)Reinforced for resisting shear used for webs (beam rib) the side inclined section.

Strengthen with the bonded prestressing in using common hot-rolled steel(HRB335,HRB400)can use level 3 compound mortar.

Composite mortar layer of protection of thickness(the distance from mortar surface to steel face) should be make sure according to the require of the durability based on the materials carbonation resistance and chemical resistance ability. Generally take $10 \sim 15(\mathrm{~mm})$, the injection thickness of the composite cement mortar is related to the reinforced arrangement. Generally take 30 40( $\mathrm{mm})$, Generally the sections which supporting angle for layout (anchor plate)have a large thickness ,so should be layered injection. 


\section{Reinforced concrete flexural members (beam or plate) should give priority to the bearing capacity of reinforcement is the unbonded prestressed concrete reinforcing scheme}

With reinforced concrete beams reinforced for example, to have a discuss about the unbonded prestressed concrete reinforcement technique. Normal section flexural strength reinforcement appropriate uses 2 strands or 3 strands of steel strand and small diameter of fine rolling rebar unbonded prestressed concrete reinforcing scheme, The inclined-section shearing resistance reinforcement Appropriate uses the scheme of transverse tension of ordinary hot rolling steel or epoxy coating hot-rolled steel (HRB400 or HRB335) which have the unbonded prestressed concrete(Fig. 2).
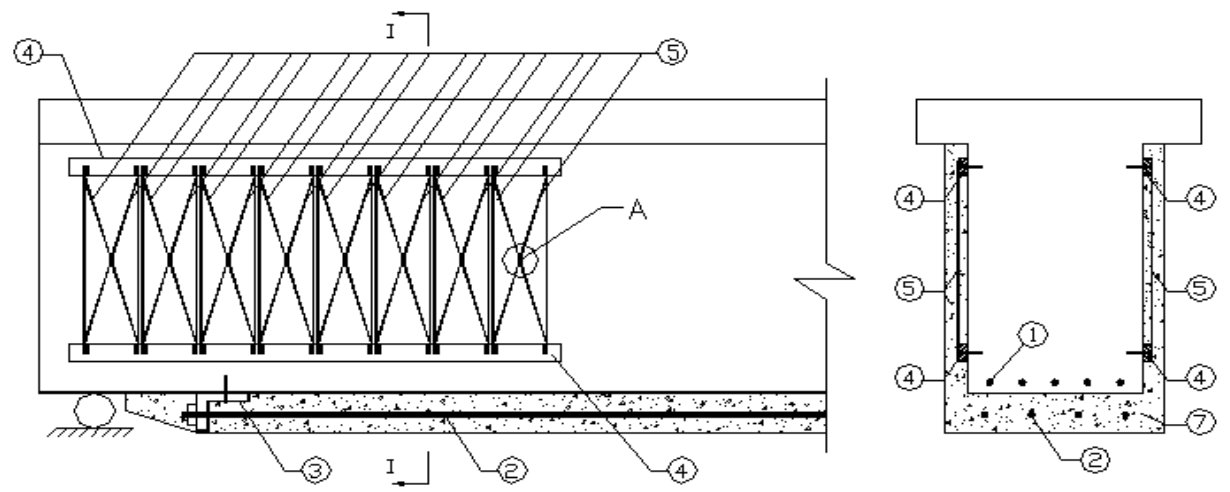

Fig. 2 The schematic drawing of the reinforced concrete beams reinforced bonded prestress structure

(1) The original beams of longitudinal reinforcement(2) Add after longitudinal tendons(3 strands of steel strand or small diameter fine rolling steel rebar) (3) Supporting anchor plate

(4) Anchorage article steel plate(5) add after transverse tension hot rolling steel vertical prestress (the dotted line shows the position before stretch-drawing, The solid line shows the position before stretch-drawing) (6) Horizontal card tight implement (7) High-powered composite mortar injected finally

Normal section flexural reinforcement. In order to improve the flexural bearing capacity of the sorghum's normal section, add small diameter steel strand (or fine rolling steel rebar) tendons in the bridge bottom. The quantity required by force, Prestressed reinforcement length should be based on the require of the beam of each section flexural strength. After the introluces' strectch-draw inject high-performance tensile composite mortar in the bridge bottom. Bond the prestressed reinforcing steel and the reinforced beam body as one to constitute the reinforcing system of unbonded prestressed concrete. (Fig. 2)

The theoretical analysis and engineering practice shows that the strengthen of the unbonded prestressed concrete reinforcing system of reinforced concrete beam of normal section and may according to the structure stress requirements and greatly improve the bearing capacity of beams is cross-section bending. The composite mortar injected in the bottom of the beam Can protect tendons from corrosion, improve the durability of structures. In addition, the high performance tensile composite mortar which injected later increased the section size of the beam. Improve the bending stiffness of the structure. It is beneficial to solve live load deformation or excessive vibration problem.

Inclined section shear reinforcement. In order to improve the shear capacity of the beam inclined section, add the vertical tendons in both sides of the beam section beam, Vertical tendons with small diameter $(6 \sim 12 \mathrm{~mm})$ of ordinary hot rolling steel (or epoxy coating hot-rolled steel), Reinforced spacing inclined section should be based on the shear capacity required force, Generally take for 200 400mm. At both ends of the prestressed steel welding fixed in the anchorage article steel webs(steel plate of the article thickness should be not less than $5 \mathrm{~mm}$ ), By adopting transverse taut deformation of tension, In the middle of the neighboring prestressed reinforcement two prestressed reinforcement on horizontal taut force, make prestressed taut hard dine in fixed Use 
transverse card tight. And then jet $30 \mathrm{~mm}$ thick high-powered composite mortar In the web on both sides of the injection then bond the prestressed reinforcing steel and the reinforced beam body as one making up the reinforcement system of prestressing inclined section(Fig. 1).

When construction the measurement and calibration of the control stress for prestressing can according the transverse tension reinforced dip Angle (or reinforced the turning point coordinates). Suppose the anchorage of steel bar between points of two welding anchorage before tension is $L_{1}$, according to the reinforced dip angle after stretch-draw $\theta$ (or reinforced the turning point coordinates) Get the tension the total length of steel $L_{2}$.from this, we can get tension control stress(Eq. 1).

$$
\sigma_{c o n}=\frac{L_{2}-L_{1}}{L_{1}} E_{P}=\left(\frac{1}{\cos \theta}-1\right) E_{P}
$$

The theoretical analysis and engineering practice shows that the strengthen by adopting transverse tension ordinary hot rolling steel bonded prestressing reinforcing system for inclined section of the reinforced concrete beam, the structure is simple and it is convenient for construction, Can effectively improve the efficiency in the use of strengthening materials, Improve the shear capacity for inclined section, the high-performance tensile composite mortar

Injected on both sides of the injection increase the thickness so can not only reduce principal tensile stress but also protect the reinforcing steel bar from corrosion, improve the disability of the structure

\section{Summing up}

The main problems of polymer mortar strengthening technology application of wire rope nets is what there is no specific provision to whether the wire rope add prestressed or not, Reinforcement mechanism is not clear, concept of chaos.

During the reinforcement of steel wire mesh in polymer mortar, if the wire rope without prestressed, Its action principle is to belong to direct reinforcement kind of passive reinforcement category. under the circumstances, the high tensile properties of the wire rope is unable to give full play to the role.

In the reinforcement of the steel wire mesh in polymer mortar, If the wire rope with prestressed concrete, Also called polymer mortar prestressed reinforcement of mesh wire rope, Strengthening the construction of the external prestressing with characteristics, Later load have the unbonded prestressed concrete characteristics, From the principle of prestressed reinforcement belongs to the category of the initiative.

The theoretical analysis and engineering practice shows that the unbonded prestressed concrete reinforcing system will be the most competitive reinforcing scheme for the comprehensive technical and economic advantages of reinforcement effect significantly, prestressed anchor structure simple and tension construction is convenient and the low cost reinforcement.

\section{References}

[1] S.R. Zhang: The eighth session of national building identification and strengthening academic exchange conference(Harbin,China,2006). p.51.

[2] L.T. Bu: the new technology of the high-powered composite mortar steel reinforced concrete structure (China Building Industry Press, China,2006)

[3] S.R. Zhang: The existing bridge reinforcement, reconstruction and evaluation of academic exchange and technical semina(Jiangshu,China,2008). p.3.

[4] S.R. Zhang: Think twice about the design concept of bridge reinforcement, J. Bridge, (2008) No.1. 